\title{
La ciudad de Ágreda y sus murallas
}

Félix Benito Martín

El estudio que se ha realizado sobre la villa de Ágreda tuvo su origen en un encargo de la Dirección General de Patrimonio y Promoción Cultural de la Junta de Castilla y León para analizar la muralla de Ágreda y su relación con la ciudad para, en consecuencia, establecer un plan o programa de actuación. El análisis de las murallas medievales de una villa castellana, con sus apartados de estudio histórico, urbanístico y físico, así como las correspondientes propuestas de intervención o planeamiento, constituía un empeño altamente sugestivo por la intensa influencia existente entre muralla y organismo urbano en la génesis y formación de las villas de la región. Bajo este prisma, y no entendiéndola como un conjunto de construcciones aisladas, fue como se contempló el análisis.

Se realizó, en primer lugar, un conjunto de análisis o estudios previos: el primero de ellos encaminado a conocer la actual situación de las fuentes documentales y la bibliografía específica, sectorial o general, relacionada con la muralla; el segundo fue el estudio histórico, derivado tanto de las fuentes documentales establecidas a través de la bibliografía analizada como de las propias sugerencias que ofrece la realidad existente, tanto en su aspecto constructivo como en el proveniente de su configuración urbana; por último el tercero se refería al planeamiento vigente y al estudio de su incidencia en la muralla, en su entorno y en su relación con la ciudad.
A continuación se desarrolló un estudio pormenorizado del estado actual del muro, realizado por tramos. Este análisis se acompañó de la subsiguiente planimetría, que comprendía el análisis en planta y el levantamiento de alzados de aquellos tramos en los que se conserva una parte sustancial del muro. También se incluyó una selección fotográfica acerca de los aspectos más relevantes de la muralla y de su estado actual.

El resultado de esta investigación se materializó en propuestas que cubren tres campos distintos: por un lado, las propuestas de investigación en el subsuelo o en el interior de las manzanas por las cuales discurre la muralla; por otro las referidas al marco normativo, fundamentalmente en cuanto afecta a su inclusión en el Planeamiento Urbanístico; finalmente las propuestas de intervención, ya sea en obras de consolidación o restauración de la muralla, ya sea en obras que deben llevarse a cabo para mejorar y acondicionar el entorno. Todas estas propuestas, complementarias ente sí, se detallaron para los diferentes tramos en los que se analiza la muralla. Se completó, así mismo, con un avance de valoración económica de las principales intervenciones sugeridas. El equipo redactor del trabajo estaba formado por Felix Benito Martín y Alicia González Díaz, arquitectos; Ana Isabel Poderoso Bravo, responsable de la investigación en fuentes documentales; Cornel Papin, dibujante y Antonio Postigo, que realizó el trabajo de levantamiento topográfico de las zonas mejor conservadas de la muralla. 


\section{Evolución histórica}

La relación entre muralla y ciudad ha sido muy importante en el desarrollo urbano durante la Edad Media tanto en Castilla como en los demás ámbitos peninsulares. La muralla, siempre presente en las villas medievales, va reflejando en su evolución física los impulsos y situaciones por las que atraviesa la ciudad. Además, la muralla influye en la configuración de la ciudad mediante su propio perímetro y, sobre todo, por la situación de las puertas, que desempeñan el papel de elementos organizadores de su estructura física. La muralla es, por un lado, un magnífico reflejo de la ciudad y, por otro, uno de los más decisivos agentes generadores de la forma urbana.

Esta realidad se pone de manifiesto de un modo muy expresivo en Ágreda. Así como en otros lugares el interés principal de la muralla se centra en sus aspectos físicos, en este caso,además de los indiscutibles valores históricos de los restos conservados del recinto musulmán, nos hallamos ante una estructura urbana de acusada complejidad, que se integra en el territorio y en la trama urbana de un modo muy intenso para dar lugar a una gran cantidad de sugerencias urbanas.

Estamos ante una estructura que ofrece una acusada singularidad dentro del panorama urbano medieval de la región. En Ágreda encontramos cuatro recintos amurallados, pero que no son fruto, como en las grandes ciudades castellanas, de ampliaciones sucesivas, sino que al menos tres de ellos son prácticamente simultáneos e independientes entre sí, salvo el recinto musulmán, que es claramente anterior. Esta simultaneidad de recintos, cuya existencia no se debe a las diferencias étnicas, tal como se ha venido sosteniendo tanto en la tradición como en la historiografía, sino casi con toda seguridad a pueblas de diferente procedencia, está mas relacionada con el urbanismo medieval de Pamplona y Estella, y parcialmente con Tarazona o Tudela.

Ágreda es una de las escasas poblaciones de Castilla que conservan restos arquitectónicos de su pasado islámico. En efecto, el recinto fortificado de La Muela ha preservado dos arcos de filiación califal que, junto con el castillo de Gormaz y la parte musulmana de la muralla de Medinaceli, son los más sobresalientes ejemplares de la región.

Estos monumentos confirman la presencia estable en un primer momento de una población musulmana en Ágreda. La mayor parte de los historiadores de la ciudad (Rabal I889; Hernández 1911; Ortego y Frías 1980) remontan la posibilidad de su fundación al inicio de la invasión, a comienzos del siglo VIII. Las crónicas medievales resaltan una primera ocupación cristiana por los navarros Sancho Garcés o su hijo García Sánchez en la primera mitad del siglo $X$.

Sea como fuere, esta actuación no llega a ser estable y toda la zona aparece controlada en la segunda mitad del siglo $X$ y a comienzos del XI por el poder musulmán, época en la que el culto cristiano convivía con el islámico. Consta en el año 927 la donación de la iglesia de S. Julián al monasterio de San Millán de la Cogolla. Estaba situada extramuros, al sur del recinto de La Muela, y sus ruinas se conservaban en pie en el siglo XIX, de tal modo que aún se pueden ver en el plano de Coello de 1860.

Gaya Nuño (1935) sostiene la posibilidad de que el monarca castellano Fernando I realizara incursiones en esta zona, ya que consta su presencia en Berlanga y otras localidades cercanas. No obstante, la seguridad de su posesión por los cristianos data de 1118 , año en que Alfonso I de Aragón conquista Tarazona, y un año después se hace con la posición de Soria en el paso del Duero, controlando el camino hacia la meseta. Ágreda, ubicada estratégicamente entre ambas poblaciones, pasó sin duda a poder aragonés en ese momento. Pero es en la época de su sucesor en Castilla, el "emperador" Alfonso VII, cuando es repoblada con contingentes humanos procedentes de las villas septentrionales, ya pobladas de antiguo: Yanguas, San Pedro Manrique y Magaña. Como ocurrió con otras poblaciones de la actual provincia de Soria -Soria, Almazán-, los pobladores, reunidos según su procedencia, se instalan en torno a una parroquia: San Martín 
de Yanguas, San Pedro Manrique o Santa María de Magaña. Estos pobladores convivieron con los mudéjares, que como ocurre con gran parte de Aragón -sobre todo en el Valle del Ebro y Somontanos del Ibérico- siguen habitando hasta su expulsión en el siglo XVI.

A partir del momento de la repoblación de los monarcas cristianos se desarrolla la estructura medieval de Ágreda, cuyo trazado ha llegado hasta nuestros días. Se trata de un conjunto de cuatro recintos independientes entre sí; La Muela, La Peña, San Miguel, San Juan. Así los denominaremos a efectos de su identificación, aunque en la memoria colectiva de Agreda aparecen denominaciones como Barrio de los Castejones, para el de Santa María de la Peña, Barrio del Mercadal, para el de San Miguel, o Barrio de la Costoya, para la zona superior del de San Juan.

La numerosísima bibliografía existente sobre Ágreda nunca ha abordado de una manera sistemática la naturaleza de tan significativa estructura urbana, sino que se ha centrado en la descripción de las iglesias, de notable valor artístico, o en los restos musulmanes, en concreto los dos arcos del Barrio de la Muela, sin duda los dos aspectos más sobresalientes en el acervo arquitectónico agredense.

La única hipótesis de desarrollo de la estructura urbana de Ágreda se debe a Juan Antonio Gaya Nuño en el referido artículo de 1935. Su hipótesis, basada en la tradición y en algunos documentos tardíos (de 1460) sobre la primera ocupación cristiana de Agreda en el siglo $X$, plantea la existencia de pueblas distintas en función de la religión de los habitantes. Según este autor, habría en Ágreda dos recintos: uno en la margen derecha del Queiles, que correspondería a La Muela, y donde estaban establecidos los musulmanes, y otro al norte del río, donde estaban asentados los cristianos. En la almedina, o zona meridional, estarían también localizados los judíos, cuya aljama se emplazaría en las cercanías del río, precisamente en la zona más alta del recinto: calle Zapatería, iglesia de Santa María de la Peña y calle del Hospital.
Esta teoría de división de la villa según las religiones y la existencia de dos o tres recintos es la que mantienen otros autores. Sin embargo, la existencia de los cuatro recintos y su trazado resulta absolutamente incontestable por los restos conservados, y no se trata de subdivisiones interiores, posteriores a la consolidación de la estructura urbana, sino de preexistencias que han generado dicha estructura. Esto se puede observar con extrema nitidez en el tramo de muralla que separa los recintos de La Peña y de San Miguel, que da origen a la ronda interior y a la exterior y al que se va adosando la edificación -parte de la cual se remonta a los siglos XV y XVI- para originar el trazado viario.

Así mismo, una precaria observación del territorio impidió a Gaya Nuño apreciar la existencia de una nítida separación entre el Barrio Moro y la zona de Santa María de La Peña y San Miguel. La configuración del terreno y el trazado de ambos núcleos no dejarían lugar a dudas sobre su discontinuidad, ratificada por los restos materiales conservados.

La existencia de recintos independientes entre las diversas etnias, en contra de lo que pretende la tradición, es muy poco habitual en las ciudades medievales de España. La convivencia entre las mismas se produjo durante cuatro siglos y de modo muy intenso, pero casi nunca en recintos independientes, sino compartiendo los mismos núcleos. Sólo al final de la Edad Media (siglos XIV y XV) aparecen "guetos" o aljamas hebraicas o islámicas, ya en épocas de creciente discriminación y nunca en pleno medievo (siglos XI, XII y $X \mathrm{III})$, período durante el cual la integración se produjo de un modo más completo.

En el actual territorio de Castilla y León no encontramos en esta época ningún recinto independiente ocupado por moriscos o judíos, al igual que ocurre en Navarra y Aragón. En esta última región, donde la presencia de moriscos fue muy intensa, se conservan muchas morerías, pero no es frecuente la existencia de un recinto independiente para los mismos. En Tudela, por ejemplo, hubo un arrabal cercado donde se ubicó la morería, 
pero coexistía con una parroquia cristiana. Lógicamente, la presencia de recintos autosuficientes divididos según étnias chocaría con el concepto de soberanía que ostentaban los regidores cristianos de las distintas villas. La distribución de las parroquias cristianas en los diversos recintos de Ágreda demuestra de forma terminante su control de todo el conjunto urbano. En el recinto septentrional se localizan las Iglesias de San Juan, San Pedro y Santa María de Magaña; en el central, las de Santa María de la Peña y San Martín de Yanguas y en el meridional, la de San Miguel.

Queda el recinto de La Muela, donde no se estableció ninguna parroquia cristiana: es el tradicionalmente denominado Barrio Moro, y en el que se conservan los dos arcos de herradura. Es posible que este recinto fuera mayoritariamente habitado por los mudéjares agredenses hasta su expulsión en el siglo XVI. La denominación tradicional, junto con la inexistencia de parroquias cristianas, corrobora dicho extremo. Estamos, sin duda, ante uno de los escasísimos ejemplos de un barrio musulmán con recinto propio en una ciudad cristiana medieval en Castilla. Sin embargo, no debemos pensar que esta existencia se reflejara en un estatuto de cierta autonomía, lo cual hubiera sido excepcional en la sociedad urbana medieval hispana. Con seguridad, la construcción de una fortaleza cristiana sobre el antiguo alcázar islámico, y cuyo resto actual es el torreón de la Mota, definiría la autoridad cristiana sobre el conjunto de la villa y, en particular, sobre el Barrio de La Muela. El emplazamiento de un barrio de etnia distinta a la dominante, ubicado junto a la fortaleza principal recuerda a las aljamas hebreas del Magreb, dispuestas en la vecindad y bajo la protección de los palacios de los sultanes y emires musulmanes.

La existencia de una calle de la Mezquita en este sector es relacionada por diversos autores con la presencia en él de la mezquita de los mudéjares. Aunque no la hemos visto reflejada en la bibliografía, consideramos estimable la hipótesis de que el solar de dicha mezquita fuera el de la ermita de la Virgen de los Desamparados, construida en el siglo XVI.
La coincidencia de esta fecha con la expulsión de los moriscos, la pervivencia de los lugares de culto y la vecindad de la citada calle de la Mezquita, abonan la verosimilitud de dicha hipótesis.

Parece, sin embargo, incuestionable que los judíos no dispusieron de propio recinto, sino que convivieron con los cristianos, posiblemente en diversos sectores de los recintos de Santa María de la Peña y San Miguel. Refuerza esta circunstancia el conflicto habido entre el poder real y los judíos de Ágreda a comienzos del siglo XV. En | 406 Don Fernando de Antequera promulga un Decreto que conmina a los judíos de Ágreda a que vivieran en su barrio, refiriéndose al hecho de que ya en 1402 el Obispo había establecido un sitio para ellos. Las autoridades de la villa confirman y señalan al monarca en | 406 que los judíos de Ágreda nunca tuvieron judería dividida.

La génesis de los cuatro recintos aparece bastante clara, tal y como se desprende de la propia estructura urbana de la villa. Los musulmanes ocupan un espolón rocoso que controla el valle del río Queiles, fácilmente defendible en su flanco occidental y en su vértice septentrional. En el flanco oriental, recayente a un arroyo tributario del Queiles, se concentra el mayor aparato defensivo. Este recinto encierra una escasa superficie, como corresponde a un asentamiento altomedieval en esta zona de la Península. El arco conservado junto a la ermita de la Virgen presenta su cara interna hacia el norte, lo cual, junto a la existencia de un importante lienzo de muralla, nos señala el área ocupada por la alcazaba musulmana, que se emplazaba en el vértice del espolón rocoso, protegida naturalmente en sus flancos. La parte más fortificada sería la que separaba la alcazaba del resto de la ciudad; es donde se ha preservado el arco y el tramo de muralla y donde posteriormente se construyó el Torreón o Castillo de la Mota, de época cristiana, seguramente en el enclave del antiguo torreón musulmán. El resto del recinto contaba con dos puertas; una, que comunicaba con el vallejo que flanqueaba la población por su borde oriental, es la Puerta del 
Barrio, actualmente conservada; la otra puerta, que constituiría el acceso principal dando origen a la arteria central que recorre el recinto por la cuerda del terreno, estaría situada en el extremo meridional $y$, una vez pasada la misma, se atravesaba la vaguada por un puente, aún conservado, que Taracena y Tudela (1928) conceptúan romano en parte.

Este es, con toda probabilidad, el recinto que encuentran los pobladores cristianos cuando a principios del siglo XII es conquistada la villa. Los otros tres recintos son generados $y$ ocupados en un corto espacio de tiempo.

En efecto, consta la repoblación de la villa por gentes procedentes de Yanguas, Magaña y San Pedro Manrique en tiempos de Alfonso $\mathrm{VII}$ (mediados del siglo XII), que levantaron las respectivas parroquias. Dos de estas parroquias, la de Yanguas y la de Magaña, cuyo origen se relaciona con dicha repoblación en el siglo XII han llegado hasta nosotros. Las otras tres iglesias -Santa María de la Peña, San Juan y San Miguel- guardan restos arquitectónicos de dicha época: en San Miguel, la torre, de finales del siglo XII; en San Juan la portada; en Santa María la estructura. De esta última consta su fundación por el Obispo Frontín en el año | 194.

La evolución de los tres recintos restantes parece, pues, que fue inmediata. Sin duda el primero de ellos fue el de Santa María de la Peña, aprovechando para ello una afloración rocosa en la margen derecha del Queiles cercana a La Muela y en una posición más elevada. Allí surgen las iglesias de La Peña y la de Yanguas, y la muralla del recinto se ciñe a la plataforma rocosa. Los pobladores procedentes de Magaña y San Pedro Manrique se establecen al norte del río Queiles, lo que da lugar a una nueva expansión urbana. En un primer momento, en torno a estas dos iglesias y a la de San Juan, se origina un trazado irregular, organizado en torno a vías longitudinales que recorren la ladera siguiendo las curvas de nivel. Estas dos calles se unen en sus extremos junto a la Puerta de la Villa, que ponía en comunicación Aragón, y la de Zaro, que lo hacía con Castilla. La calle de cota inferior flanquea la iglesia de San Pedro y la superior la de San Juan. La iglesia de Magaña se emplaza en el extremo oriental del recinto, adosada a la muralla, en la zona estratégica, enfrentada al conjunto fortificado de La Muela. En torno a las tres iglesias y sus cementerios surgen los únicos espacios abiertos de este barrio, cuya constitución topográfica, al contrario que los de La Muela (espolón rocoso) o de Santa María de la Peña (plataforma), es de ladera.

La parte superior del recinto obedece a un trazado más regular, con calles paralelas que recorren el tejido manteniendo la cota y transversales que ascienden por la pendiente. Este recinto, el de mayor superficie de Ágreda, constaba de tres puertas: al norte, la de Añavieja, actualmente conservada; la de la Villa, que comunicaba con Tarazona; y la de Zaro, en el extremo occidental, que ponía en contacto con Soria. Hacia el río se abrían también otras puertas, de una de las cuales tenemos segura existencia por un testimonio gráfico (Moreno 1957). Aparece en esta fotografía la calle que desciende desde la puerta de la Villa a la Plaza, anteriormente hacia el puente sobre el río Queiles, y que comunicaba con la calle del Hospital, ya en el recinto meridional. Al fondo, cierra la vía la fachada en escorzo del santuario de la Virgen de los Milagros. En el lugar donde se situaba la muralla existe una puerta con arco de medio punto y hornacina superior parecida al Arco de Santo Domingo, que da origen a la calle del Hospital.

El cuarto recinto es el de San Miguel, adosado a La Peña. Es, sin duda, sucesivo en su formación, ya que está a un nivel inferior y la muralla que los separa se apoya en el escalón rocoso de la plataforma antes citada. Este recinto de San Miguel es, después del de San Juan, el que goza de mayores proporciones en Ágreda y está asentado en una ladera, aunque su zona central, donde se extiende la plaza del Mercadal y se alza la iglesia de San Miguel, es casi llana.

En el punto de contacto con el recinto de La Peña se genera una ronda extramuros al anterior recinto definida por las edificaciones reclinadas en el repliegue exterior a la muralla. 
En los extremos de esta calle se abrían dos puertas: una de ellas flanquea la Torre del Tirador -la Puerta de Santiago- simétrica a la Puerta de Almazán antes señalada, en una solución única en el urbanismo castellano; y en el otro extremo, otra puerta pondría en contacto este recinto con el Barrio de La Muela.

Una tercera puerta se abría en el extremo sur, en el camino de Vozmediano. Sería así simétrica de la de Añavieja, y entre ambas quedaría comprendido el eje transversal del conjunto urbano de Ágreda. Esta puerta, Ilamada Puerta Nueva, aparece todavía en el plano de Coello de 1860. En el extremo sudoccidental pudo haber existido otra puerta, tal como se refleja en la estructura del viario intramuros y en la configuración de los caminos extramuros. El Arco de los Pilares, en la calle Central, separaba y ponía en contacto este recinto con el de La Peña.

La independencia de los tres recintos de La Muela, La Peña y San Juan responde a las imposiciones o barreras del territorio; sin embargo, la extensión del recinto de San Miguel no sigue la dinámica habitual de las ciudades castellanas, en las que el recinto primitivo queda englobado en el resultante, sino que se asemeja más a la articulación en pueblas independientes de las ciudades navarras -Pamplona, Estella-. En efecto, el arco de la calle Zapatería continúa existiendo y la muralla sigue operando como barrera entre ambos recintos. Cabe, pues, resaltar la profunda originalidad de la estructura urbana de Ágreda, auténtico enclave y punto de contacto entre el urbanismo castellano, navarro y aragonés. En esta situación queda consolidada la evolución urbana de Ágreda en la Edad Media y así permanecerá desde el siglo XIII hasta el siglo XV.

Finalmente, otro factor añade un plus de interés al conjunto de Ágreda. Se trata de las importantes intervenciones habidas en el siglo $X V I$, que, aunque muy selectivas en su magnitud, transforman radicalmente la configuración de la ciudad. En efecto, en esa centuria se produce una operación tan llamativa como es la cubrición del río Queiles con la creación, junto con la Plaza Mayor y el Consistorio, de un nuevo centro para la villa. A su vez la importante implantación del palacio de los Castejones altera el recinto de San Miguel y su conexión con el de La Peña y el de La Muela debido a la construcción de una nueva puerta. Ambas actuaciones persiguen y consiguen un mismo fin: disminuir las barreras entre los recintos y plantear un continuo en la vialidad urbana.

Estas grandes transformaciones renacentistas de Ágreda comienzan con la citada cubrición del río Queiles, para lo cual se construyó un túnel de cuarenta y cinco metros de largo, siete de ancho y siete de alto. Sobre dicho espacio se extiende la nueva Plaza Mayor y se construye el Ayuntamiento. La obra empieza a desarrollarse en el año |55| y supone una radical transformación de la villa, ya que propicia la conexión entre los dos sectores a ambos lados del río. La Plaza Mayor y el Ayuntamiento se sitúan frente a la calle Zapatería, mientras que más hacia el este se encuentra el puente de la Lobera, que comunica la calle de la Virgen, al norte, con la del Hospital, al sur. Sólo en tiempos recientes se cubrió el espacio entre dicho puente y la Plaza Mayor.

Más hacia el este se construye en 1557 el convento de Agustinos Calzados, cuya iglesia es la actual parroquia de Nuestra Señora de los Milagros. Este convento ocupa con su templo, establecimientos claustrales y huertas una gran extensión extramuros entre el espolón donde se localiza la iglesia de Magaña y La Muela.

La implantación del nuevo palacio de los Castejones, a finales del siglo XVI, constituye la otra gran intervención renacentista. Este edificio, de considerables proporciones y con un extenso jardín, se construye a espaldas de la iglesia de San Miguel, en el flanco nororiental de este recinto, mirando hacia el barrio Moro. Para ello se realiza una operación de gran envergadura que altera los perfiles topográficos del lugar. Por un lado, se manifiesta en la alineación extramuros del palacio y del jardín, que se replantea recta y con una gran longitud, y avanza siete metros sobre la anterior línea de muralla, que estaba apoyada en 
un repliegue rocoso. El palacio se construye sobre un semisótano de dos alturas, cuya finalidad es conseguir una superficie plana de mayor extensión sobre la que asentar las plantas nobles. En la cara interior de estas crujías se observa hoy día el escalón rocoso en el que con toda seguridad se sustentaba la antigua muralla.

La nueva intervención del siglo XVI redefine todo el borde del recinto transformándolo en una línea recta. Por otro lado, eleva la cota inferior de la vaguada, que lo separa del Barrio Moro, tal como se desprende de la observación del puente de acceso al mismo, sin duda más esbelto en origen que en la actualidad.

Como consecuencia de esta intervención, se redefinen las puertas de los recintos de Santa María de la Peña y de San Miguel y se construye el arco de Felipe II, en el que consta la fecha de su apertura, 1573. Este arco, en su estado actual, sirve de acceso a ambos barrios, pues en él confluyen dos vías: una procede de la calle Ancha y plaza del Mercadal, en el recinto de San Miguel, y otra, la calle del Hospital, del recinto de Santa María de la Peña. No conocemos cómo sería la disposición exacta de los arcos que anteriormente daban paso a ambos recintos sobre las calles antes enumeradas, pero es muy posible que se repitiera una situación similar a la que se produce en el extremo opuesto a ambos lados de la Torre del Tirador.

Todas las actuaciones del siglo XVI transformarán el espacio de los nexos de unión entre los diversos recintos, creando un continuo urbano que hace disminuir la naturaleza compartimentada del tejido surgido en la Edad Media, con lo cual la percepción del conjunto y sus relaciones quedan definitivamente fijadas con una nueva visión, en esta época. La zona del Queiles, antes punto de separación y articulación entre recintos distintos, se convierte ahora en el centro de Ágreda. Con menor intensidad, pero también de un modo notable, se ha disminuido la barrera espacial y perceptiva entre el recinto de La Muela y los vecinos barrios de La Peña y San Miguel. Esta intervención del siglo XVI, tan trascendente desde el punto de vista de la funcionalidad urbana, refuerza también la singularidad de Ágreda, lo que la convierte en una de las poblaciones más notables de Castilla en relación con su evolución urbana.

\section{Diagnóstico y propuestas derivadas del estudio}

El estado físico de conservación de las murallas de Ágreda es muy deficiente, ya que los elementos en buen estado se circunscriben básicamente a las numerosas puertas y a los tres torreones principales. En la zona de La Muela existen también tramos de muro islámico de indudable valor.

En conjunto, y dejando al margen el recinto de La Muela, se puede afirmar que el interés de las murallas de Ágreda se centra mucho más en su valor histórico y en la riqueza de sugerencias urbanísticas que en su significado físico.

Por otro lado, estamos ante un recinto de relativa extensión, fuertemente consolidado, donde la edificación se ha adosado sistemáticamente a la cara interior de los muros y en ocasiones también externamente. Esto va a definir una actuación de alineaciones poco drástica, muy conservadora, que casi siempre mantiene el entramado actual heredado sin intentar liberar la muralla de los añadidos posteriores, los cuales, debido a la antigüedad de estos adosamientos, han adquirido un valor histórico y ambiental indudable. No obstante, esta norma general va a sufrir las necesarias adecuaciones y matizaciones que precisa un trazado tan variado y complejo como es el de las murallas de Ágreda.

La actuación de restauración y conservación del muro se centra en los restos singulares subsistentes y sobre todo en el recinto de La Muela. Allí nos encontramos con el muro sudeste, a ambos lados de la Puerta del Barrio, en pleno proceso de descomposición y cedimiento. El muro ubicado al sudoeste del arco es de traza islámica y encierra un enor- 
me valor. Esta es sin duda la principal y más urgente intervención, que consiste en consolidar dichos muros y recomponer en lo posible, de forma documentada, los puntos que actualmente han cedido.

En los demás lugares no se aprecia una necesidad urgente de intervención, si bien hay que tener un especial cuidado en el seguimiento de la zona de La Muela por las numerosas oquedades kársticas del subsuelo.

Recientemente se ha actuado en las dos puertas musulmanas y en la Torre del Tirador. El resultado estético y ambiental de esta última intervención quizá requiera, aunque sin urgencia, una segunda fase en labores de acabado. En cuanto a la obra de adecuación del entorno de la Puerta del Barrio, debe considerarse insatisfactoria y necesitada, también a medio plazo, de una modificación parcial que elimine los efectos negativos de la misma.

Precisamente, en el recinto de La Muela se plantean las dos intervenciones más ambiciosas relacionadas con la muralla. Una de ellas es la recuperación del espolón de La Muela como Espacio Libre Público, para lo cual habrá de ser adquirido. Esta zona era el enclave de la antigua Alcazaba, origen de la evolución urbana de Ágreda. Resulta vital recobrar este espacio, en primer lugar, para la realización sistemática de excavaciones que den luz a la historia de la villa; en segundo lugar, por el valioso mirador, que supone una espléndida localización para un parque o zona verde, y en tercer lugar, por la propia circunstancia de ser el solar de la primitiva Alcazaba.

La otra actuación es la recuperación del valle del Queiles al pie de La Muela. Estamos ante un ámbito de primera magnitud por su calidad ambiental, bien conservado por su escaso uso y desde el cual cobra gran parte de su verdadera magnitud la imagen del primer recinto musulmán. Es una zona profundamente degradada en cuanto a uso, sobre todo por su inaccesibilidad y por la ubicación del colector de la población. Se plantea recobrar globalmente el espacio, lo que incluye los dos molinos -en ruinas, pero de valiosa arquitectura popular-. Para ello, las intervenciones estratégicas previas son la construcción del colector hasta el pie de La Muela y la creación de los accesos, obras que no resultan costosas. A partir de ahí, las actuaciones que deben llevarse a cabo en el paisaje han de ser muy prudentes y conservadoras. El paisaje, una vez restaurado de su degradación funcional, presenta un enorme potencial de uso y autorregeneración.

Las demás actuaciones son siempre concretas, encaminadas a mejorar o poner en valor determinados tramos, manteniendo siempre como norma general las labores de investigación -en suelo privado, antes de construir, y en suelo público, en los momentos de realizar las infraestructuras- y de catalogación, evitando derribos de una muralla que, aunque queda oculta en el interior de las manzanas, tiene una existencia que debe ser respetada.

Fuera de La Muela, el ámbito de mayor interés es el entorno de la Torre del Tirador, con las dos puertas que la flanquean y penetran en sus diferentes recintos. Además de su valor por la singularidad urbanística, el enclave presenta una alta calidad ambiental que se presta a una actuación de conjunto en toda la plaza hasta el torreón situado en el extremo septentrional, la cual consistirá en una adecuación del pavimento y sobre todo un tratamiento de la fachada urbana comprendida entre los dos torreones -el del Tirador y el situado en el extremo norte de la plaza-. Este tratamiento consistirá básicamente de la restauración de las superficies visibles del muro y la introducción de un color neutro en los revocos que se han de realizar en los muros cuya imagen es absolutamente negativa.

En todo el flanco norte se desarrollará la tercera intervención entre el Torreón de la Costoya y el extremo noroeste del recinto. Se trata aquí de consolidar los tramos preservados en primer lugar, ir retranqueando las puertas en los huecos que se han abierto en la muralla, mejorar la pavimentación con una adecuada introducción de elementos vegetales $y$, finalmente realizar revocos de carácter neutro en las fachadas más agresivas. 
No obstante, esta última actuación es la menos urgente en el programa de intervenciones, ya que los elementos conservados presentan menor relevancia que en otros tramos, así como el conjunto ambiental.

\section{Actuaciones de Investigación}

Uno de los aspectos más destacados de las propuestas es precisamente el relativo a las futuras investigaciones. El rastreo sistemático de las diferentes murallas que este estudio encierra encuentra precisamente una de sus mayores virtualidades en la capacidad de definir con precisión las hipótesis de localización de los vestigios arqueológicos. Esta situación servirá de guía para ulteriores investigaciones que se realizarán cuando surja alguna circunstancia que así lo aconseje. En los distintos planos se marcan los puntos donde deberá procederse a dicha investigación.

La investigación será de dos tipos según el ámbito donde se haya de efectuar: suelo público o privado. En las parcelas privadas en las que se define la necesidad de investigación es a efectos de remoción del subsuelo en el momento de nueva construcción o derribo total de un inmueble. Se vigilará la obra citada con supervisión arqueológica para detectar los restos de muro, documentarlos y ver su disposición.

En los lugares marcados en suelo público, se trata de investigar la posible existencia de tramos de muralla o la ubicación precisa de determinadas puertas. La investigación puede llevarse a cabo como iniciativa específica a tal fin o aprovechar la remoción del subsuelo derivada de la construcción o reparación de infraestructuras (agua, alcantarillado, energía eléctrica, teléfonos, pavimentación). En tal caso, antes de comenzar la citada obra se procederá a la excavación con metodología arqueológica con el fin de realizar una investigación completa y detectar los restos buscados del muro.
Se pretende así corroborar y conocer con exactitud la existencia de las puertas no conservadas de los diversos recintos: puerta sudoeste del recinto de La Muela, Puerta Nueva y puerta sudoeste del recinto de San Miguel, puerta junto al actual Ayuntamiento en el recinto de Santa María y, en el recinto de San Juan, Puerta de Zaro, Puerta de la Villa y puertas meridionales. Así mismo, tendrá un gran interés conocer los tramos que se presentan como hipótesis en los recintos, tales como los posibles arcos anteriores al arco del siglo XVI, vecinos del Palacio de los Castejones, o esclarecer cómo entroncaban los tramos de muro existentes en la zona de la Torrecilla con la Puerta Nueva, por un lado, y con la zona del Jardín del Palacio de los Castejones, por otro.

Todo este conjunto de propuestas y programas de actuación se encaminan conjuntamente a poner en valor una muralla de difícil percepción visual pero de gran interés para la comprensión de la ciudad y su historia.

\section{BIBLIOGRAFÍA}

GAYA NUÑO, J. A. (1935): "La muela de Ágreda: Restos de la almedina fortificada y de la aljama hebrea". Boletín de la Academia de la Historia, vol. 106, pp. 271285.

HERNÁNDEZ, J. (|9| I): Historia de Ágreda. Tarazona. Imprenta Félix Meléndez.

MORENO MORENO, M. (1957): Por los pueblos sorianos: páginas de la historia, del arte y del paisaje. Soria. Casa de Observación.

ORTEGO Y FRÍAS, T. (1980): Ágreda: Bastión de Castilla hacia Aragón. Soria.

RABAL DÍEZ, N. ( I 889): Soria. España: sus monumentos historia y arte. Barcelona, Daniel Cortezo.

TARACENA AGUIRRE, B.; TUDELA, J. (1928): Guía artística de la ciudad y su provincia. Soria. Imprenta Las Heras. 


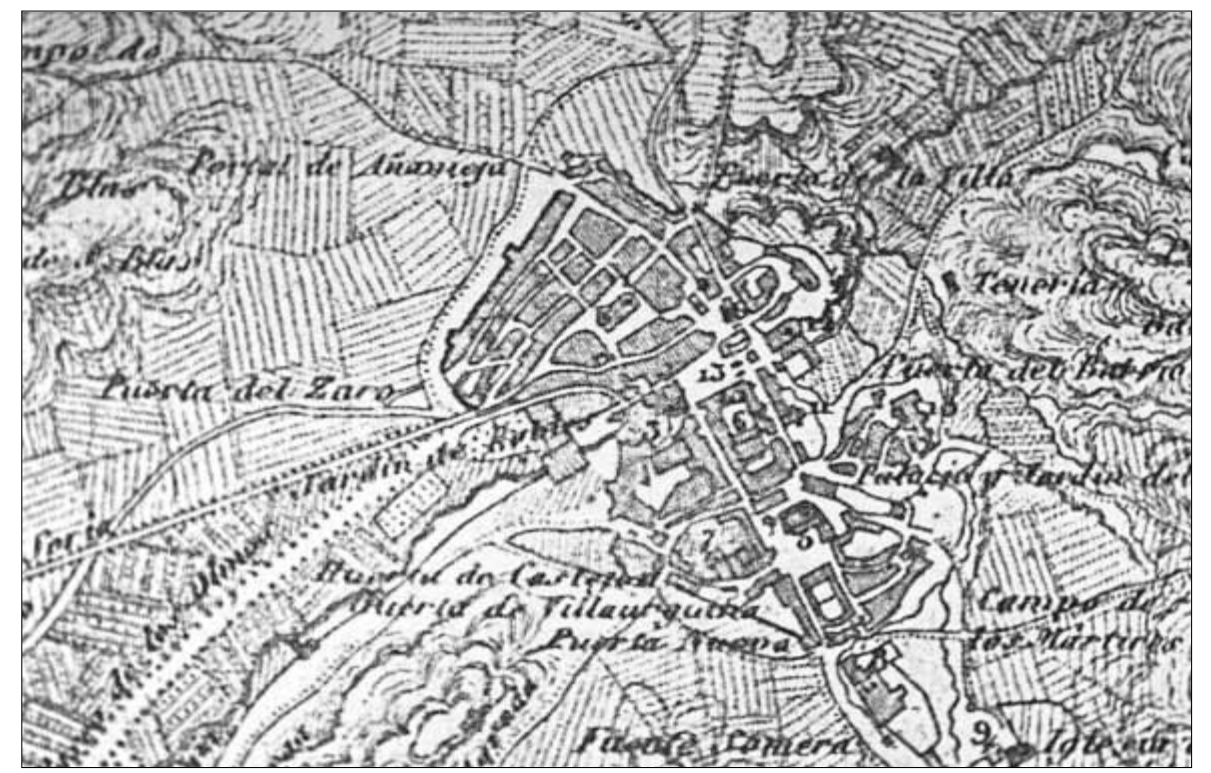

I. Plano de Coello. Siglo XIX. Se aprecia cómo se consevaban intactos los cuatro recintos y algunas puertas hoy desaparecidas

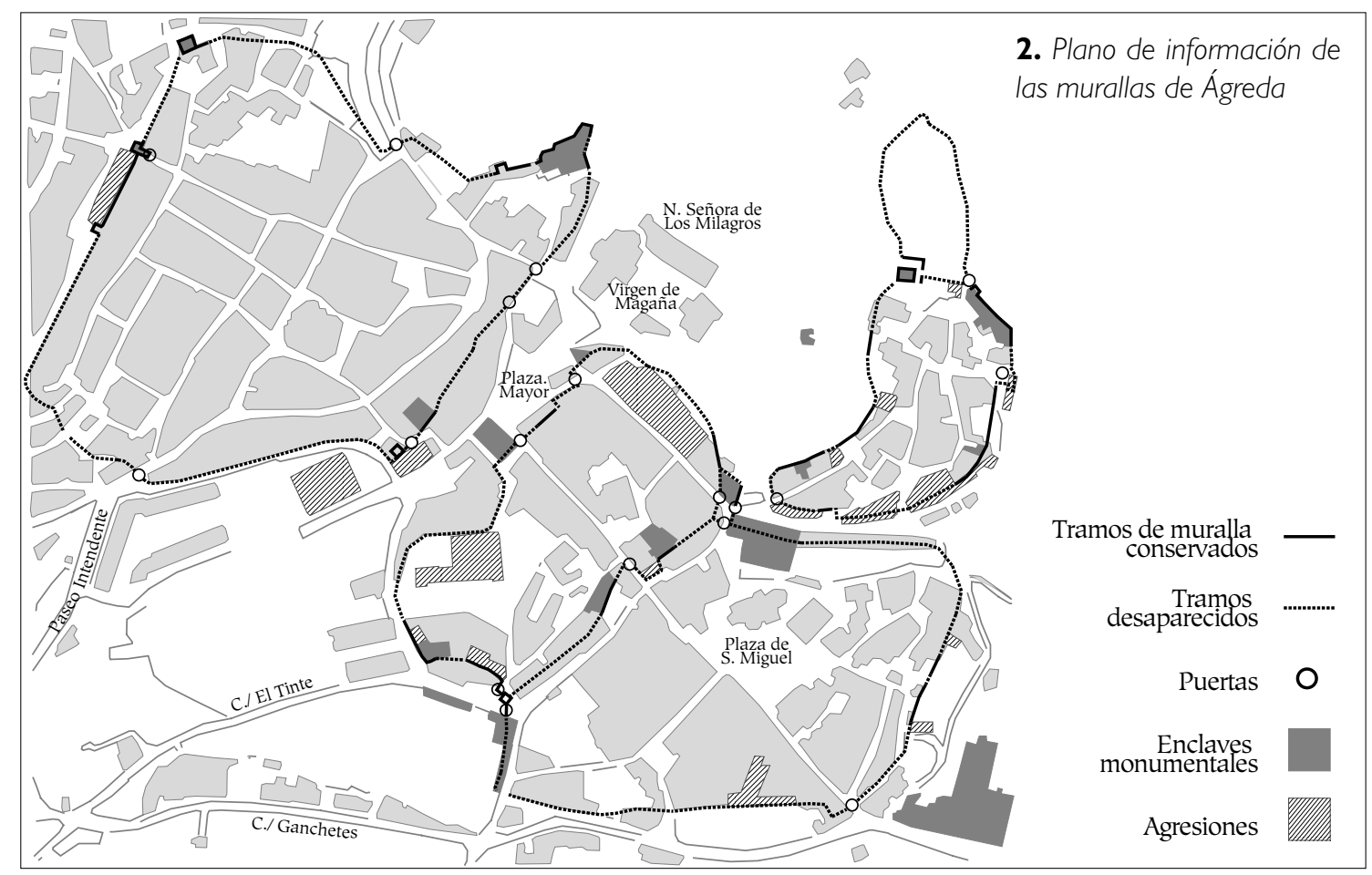

3. Vista general de Ágreda de un grabado del S. XIX

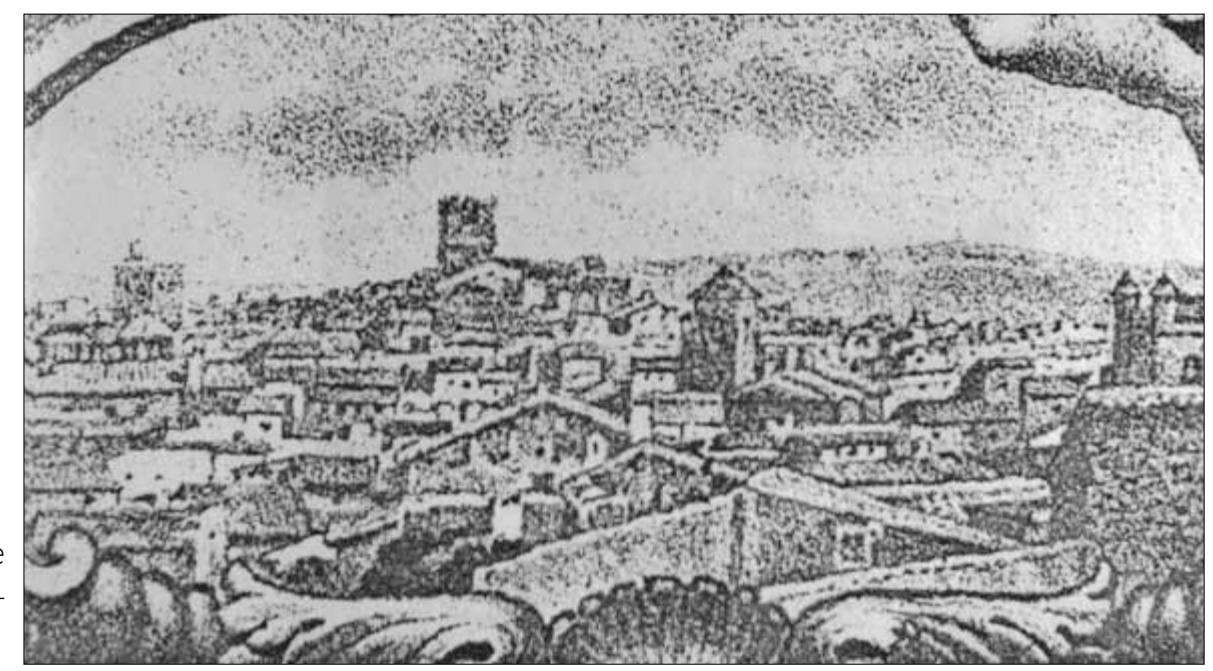




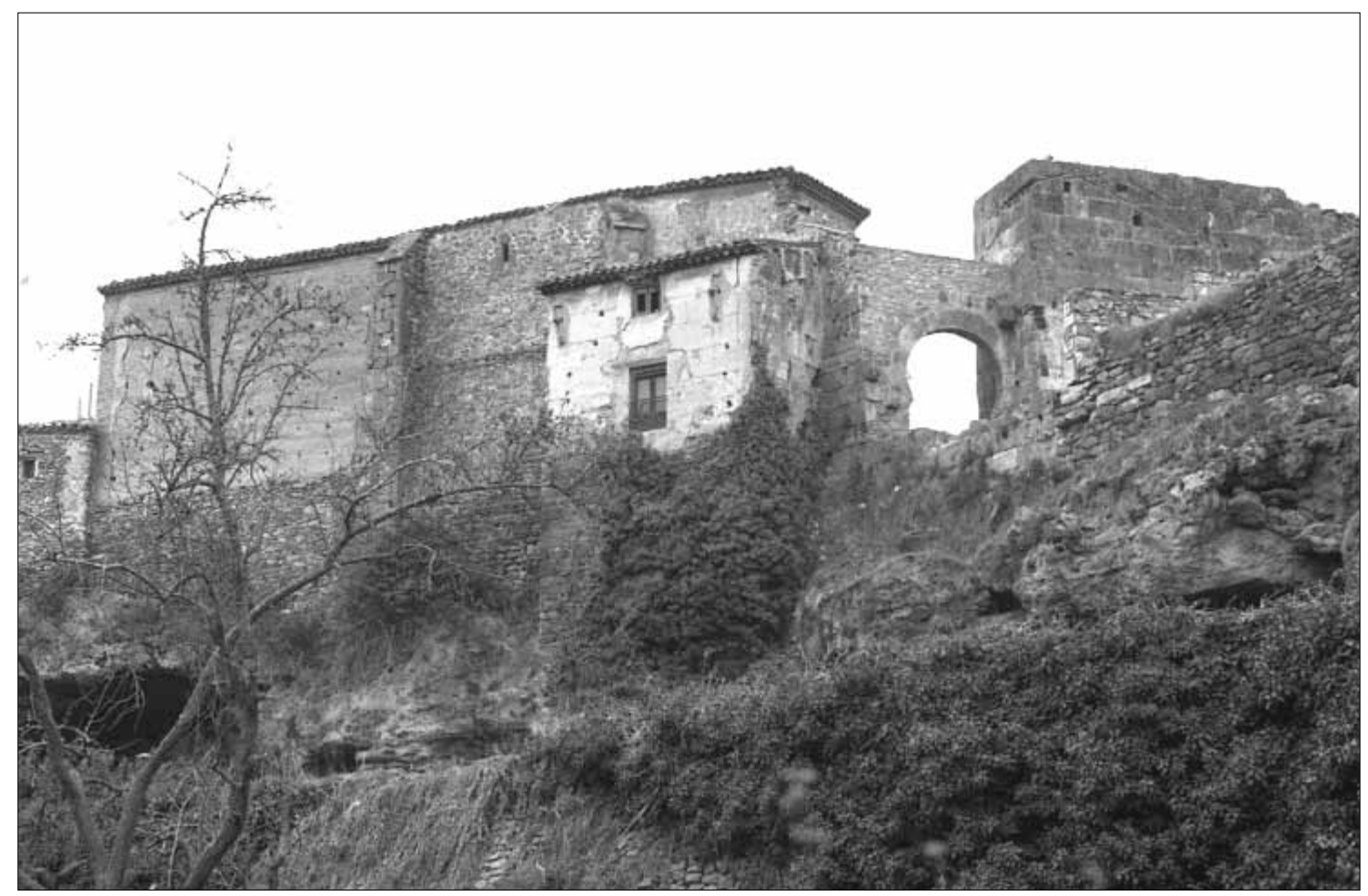

4. Puerta de la Muela, de arquitectura islámica, junto con el adyacente muro de la Alcazaba y ermita de los Desamparados

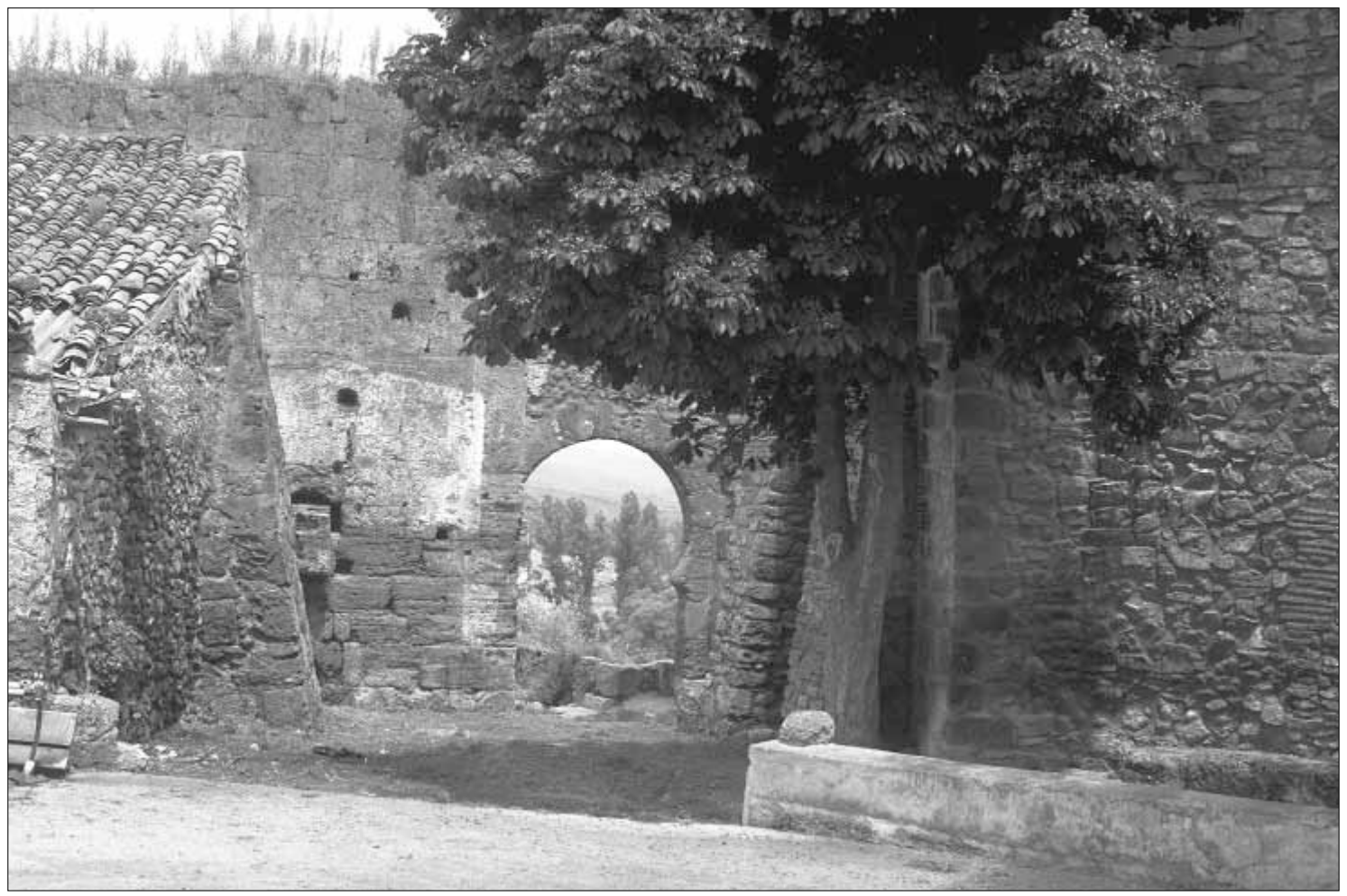

5. Puerta de la Muela 

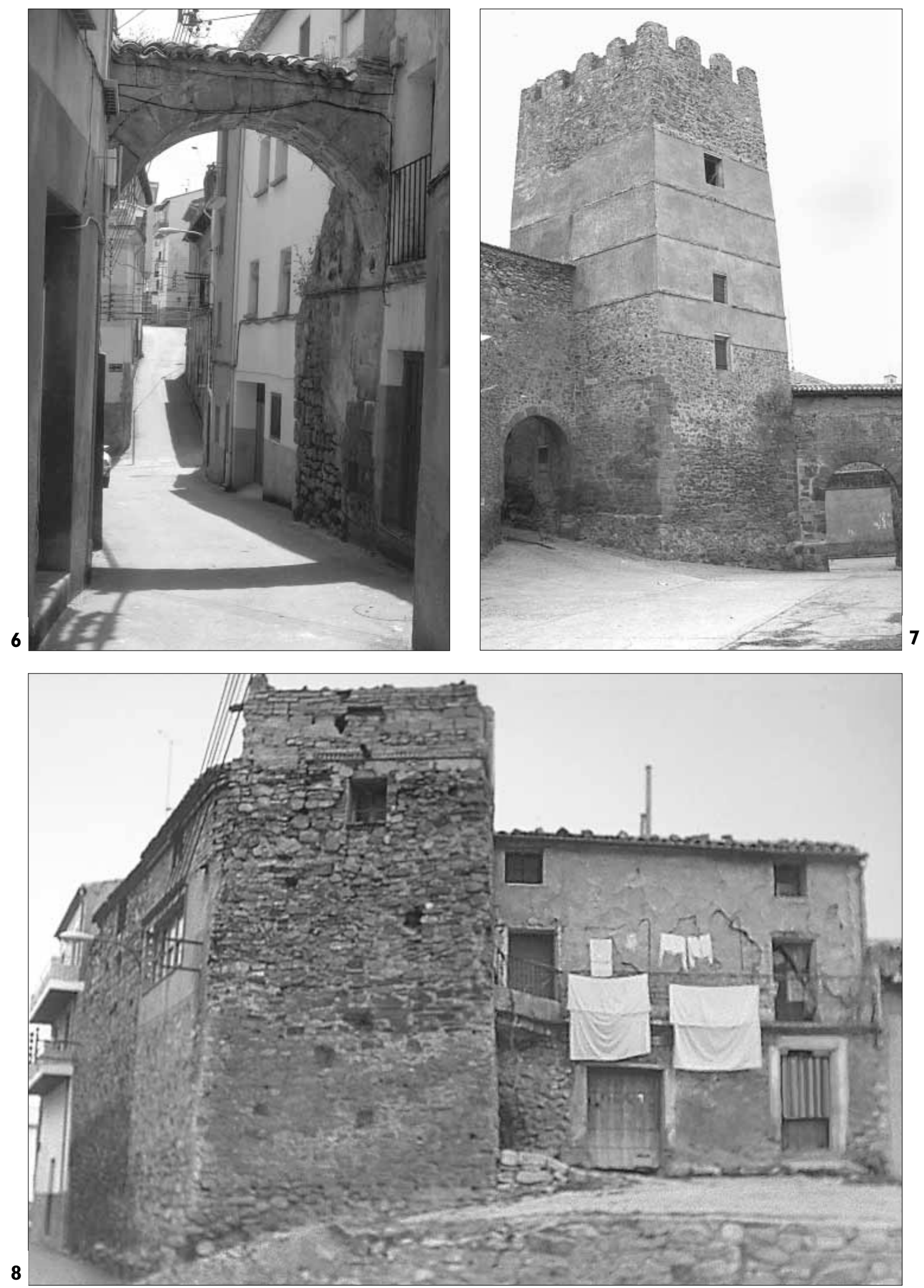

6. El arco de la calle Zapatería separaba dos recintos entre sí: el de La Peña y el de San Miguel.

7. Torre del Tirador, flanqueada por las puertas de muralla de los dos recintos contiguos. Es una situación única en el urbanismo castellano. 8. La edificación tradicional de Ágreda se adosó desde antiguo a la muralla 

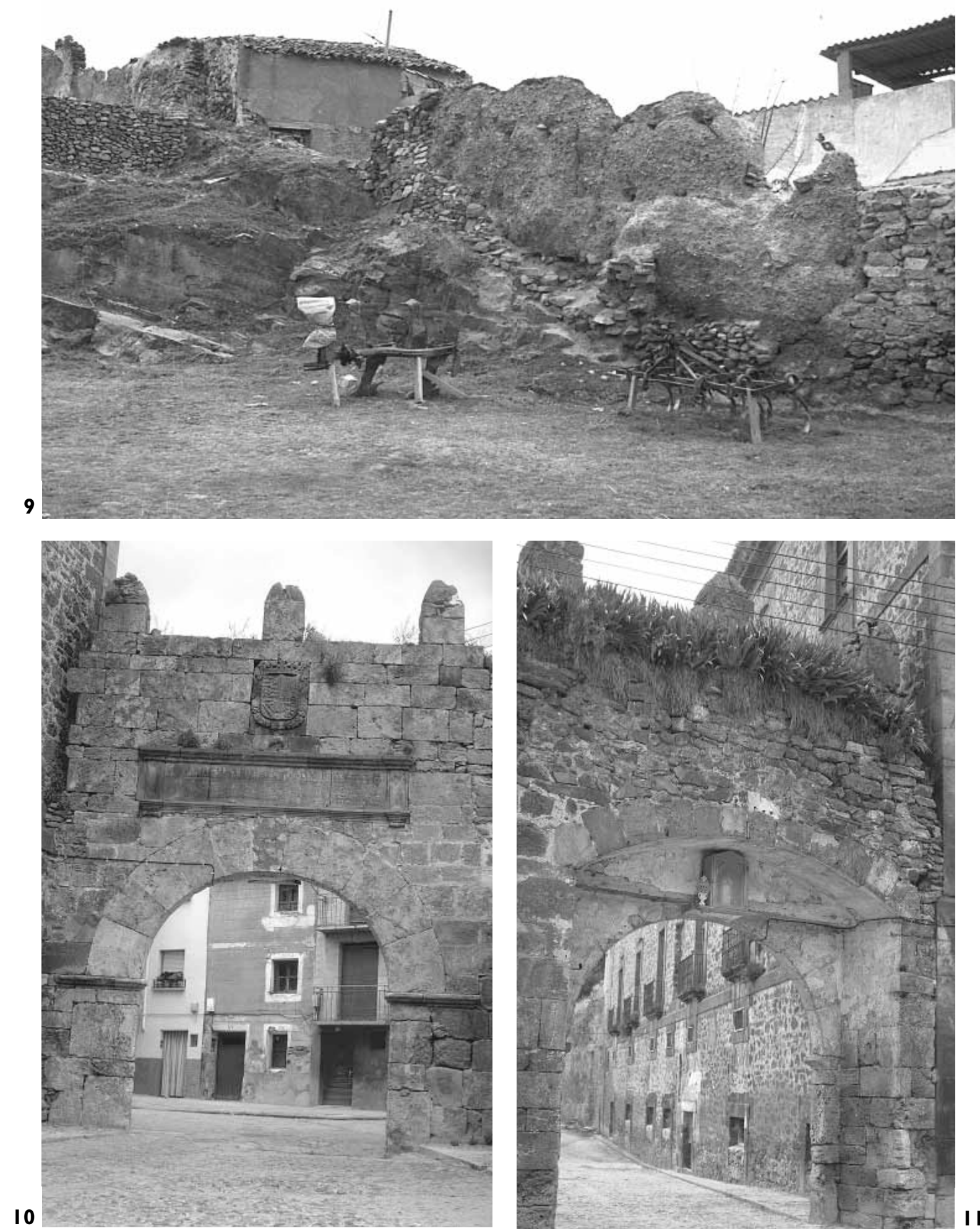

9. El muro de los recintos exteriores se componía de un alma de tapial y dos caras exteriores de mampostería. I 0-I I. El arco de los Castejones o de Felipe II se construyó en 1573, con motivo de una reordenación urbanística que contribuyó a acercar los recintos de la Peña y de S. Miguel con el de la Muela 

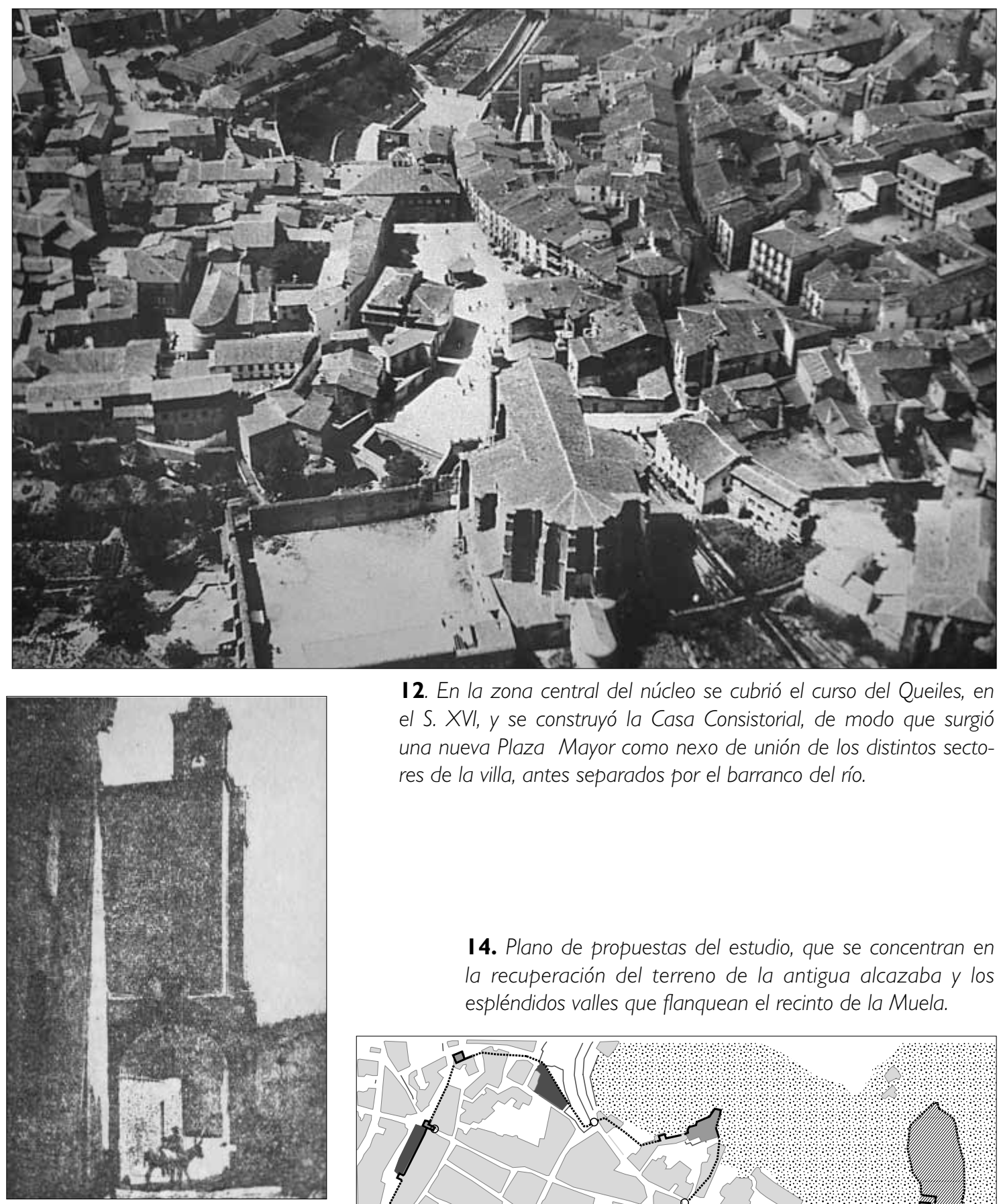

13. De una foto antigua conocemos la naturaleza de la puerta de la muralla que comunicaba el recinto de S. Juan con el río.

12. En la zona central del núcleo se cubrió el curso del Queiles, en el S. XVI, y se construyó la Casa Consistorial, de modo que surgió una nueva Plaza Mayor como nexo de unión de los distintos sectores de la villa, antes separados por el barranco del río.

14. Plano de propuestas del estudio, que se concentran en la recuperación del terreno de la antigua alcazaba y los espléndidos valles que flanquean el recinto de la Muela.

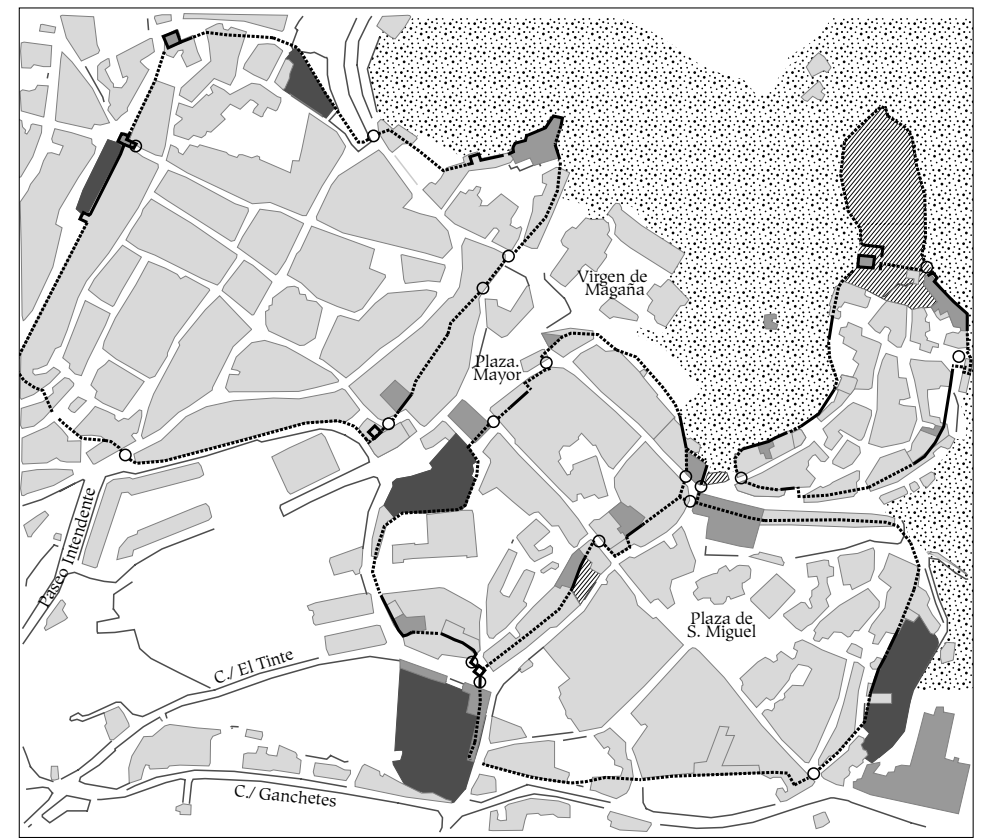


15. La puerta califal del Barrio, según un grabado antiguo.

16. La reciente restauración de la Puerta del Barrio, realizada con el loable propósito de proteger su integridad, ha producido su descontextualización, al

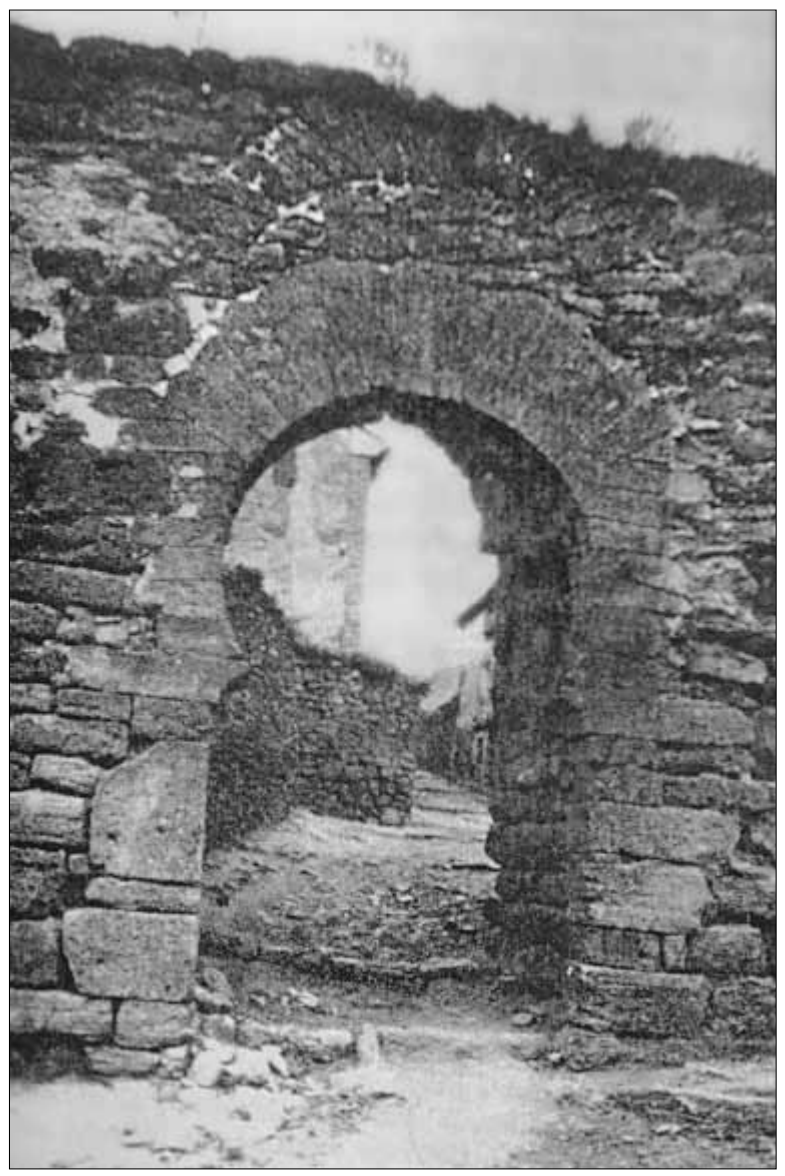
suprimir el paso bajo la misma

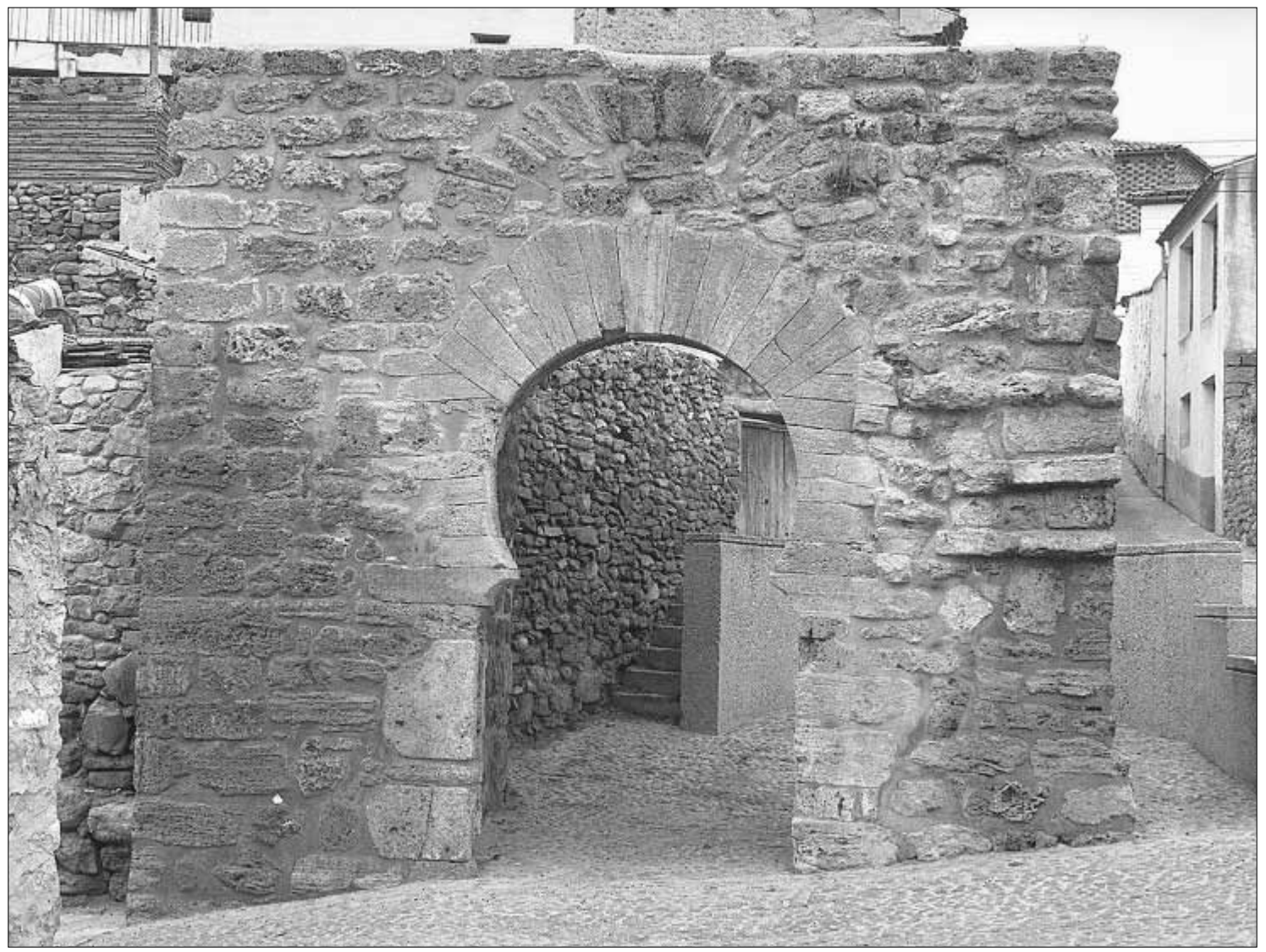




\section{a}
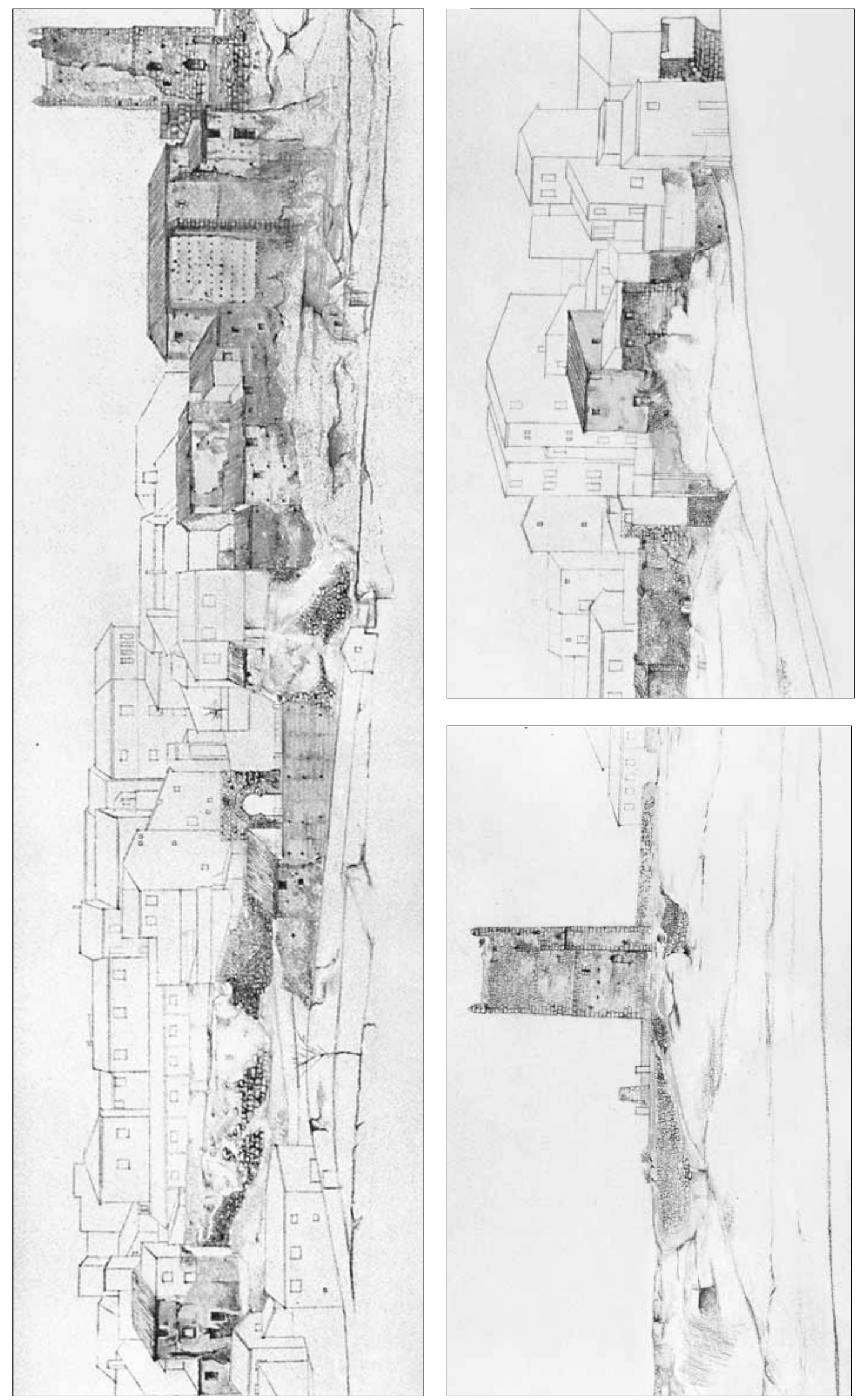

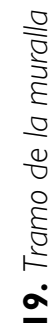

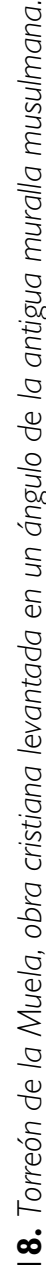

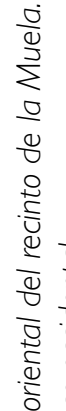

ن

है

ब

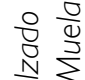

₹

동 